\title{
EVALUATION OF LOW BACKACHE IN RURAL FOLK
}

\author{
Ch. Laxmana Rao', K. Ravikumar Varma², K. Tripura ${ }^{3}$
}

${ }^{1}$ Associate Professor, Department of Radiology, Maharaja Institute of Medical Sciences. ${ }^{2}$ Assistant Professor, Department of Radiology, Maharaja Institute of Medical Sciences. ${ }^{3}$ Senior Resident, Department of Radiology, Maharaja Institute of Medical Sciences.

\begin{abstract}
\section{BACKGROUND}

Degenerative disease of the spine is a major cause of low back pain. In the absence of trauma degenerative disorders of the lumbar spine is the main aetiological factor followed by infective aetiology. The approach to a patient with low back pain starts with a careful and detailed history including the mode of onset, duration of pain, aggravating and relieving factors. Our study is to evaluate the exact aetiology of back pain in rural population with MRI investigation.
\end{abstract}

\section{MATERIALS AND METHODS}

We have selected patients from rural background from the villages in and around Nellimarla, Vizianagaram, in the age group of 20 to 60 years. Main criteria for the study is patients with chief complaint of low back pain with no history of trauma. The study was performed on Toshiba 0.2T MRI Scanner using spine - array coils.

\section{CONCLUSION}

In conclusion we suggest that MRI evaluation of backache as high sensitivity and specificity even though MRI is over suggested to patients for evaluation of backache. We also found that infective aetiology is not the main factor for backache in rural population.

\section{KEYWORDS}

Degenerative Changes, Disc Dehydration, Disc Herniation, Early Degenerative Changes, End Plate Changes, Ependymoma, Infective Spondylitis, Infective Spondylitis-Tuberculous Aetiology, Low Back Pain, Metastases, Multiple Myeloma, Osteophytes, Sciatica, T1 Weighted Imaging, T2 Weighted Imaging.

HOW TO CITE THIS ARTICLE: Rao CL, Varma KR, Tripura K. Evaluation of low backache in rural folk. J. Evolution Med. Dent. Sci. 2016;5(81):6018-6024, DOI: 10.14260/jemds/2016/1359

\begin{tabular}{|c|c|}
\hline BACKGROUND & Tuberculous osteomyelitis of the spine, which is a common \\
\hline Low back pain is one of life's most common infirmity and & entity in the Indian subcontinent usually manifests as an \\
\hline time during their life, $80 \%$ of all people will experience back & The approach to a patient with low back pain starts with a \\
\hline pain, a common reason for loss of time from work. There are & careful and detailed history including the mode of onset, \\
\hline many potential sources of pain and finding the specific cause & duration of pain, aggravating and relieving factors. \\
\hline is often a confounding problem. & Evaluation of low back pain requires assessment of the \\
\hline $\begin{array}{l}\text { Horenstein defines chronic low back pain as localised to } \\
\text { the lower back that has persisted for more than } 90 \text { days, does } \\
\text { not disappear upon treatment and results in any degree of } \\
\text { disability. }\end{array}$ & $\begin{array}{l}\text { vertebral column, the central spinal canal contents and } \\
\text { paraspinal soft tissues. As persistent low back pain is the most } \\
\text { common cause of morbidity, the need for prior detection of the } \\
\text { cause is necessary. }\end{array}$ \\
\hline Disorders associated with back pain usually have two & The aim of this study is to evaluate the exact aetiology in \\
\hline components. One pertains to the spinal disorder itself and the & rural preparation and to find out whether they are under- \\
\hline other to the symptoms and signs that result from compromise & investigated or over-investigated due to high cost of MRI scan, \\
\hline $\begin{array}{l}\text { of individual nerve roots, the cauda equina or in some cases } \\
\text { the conus medullaris. }\end{array}$ & $\begin{array}{l}\text { which most of the rural population could not afford as their } \\
\text { annual income is much below the national average annual }\end{array}$ \\
\hline In the absence of history of trauma, low back pain of & We studied 240 patients in the last three years, i.e. \\
\hline musculoskeletal origin is known to occur commonly due to & from May 2013 to May 2016, all having a rural background and \\
\hline $\begin{array}{l}\text { degenerative disorders of the lumbar spine. } \\
\text { Vertebral osteomyelitis and neoplastic lesions (Primary or }\end{array}$ & $\begin{array}{l}\text { most of them are agricultural labourers and farmers. All of } \\
\text { them are in the age group of } 20 \text { to } 60 \text { years. }\end{array}$ \\
\hline
\end{tabular}
secondary) of the spine often present with low back pain.

Financial or Other, Competing Interest: None.

Submission 20-07-2016, Peer Review 02-09-2016,

Acceptance 10-09-2016, Published 07-10-2016.

Corresponding Author:

Dr. K. Ravikumar Varma,

49-18-15/1, Mithila,

Lalitha Nagar,

Visakhapatnam -16.

E-mail: drkrvarma@yahoo.com

DOI: $10.14260 /$ jemds/2016/1359

\section{MATERIAL AND METHODS}

The present study was conducted on 240 cases of low back pain, attending the Orthopaedic and Neurological Outpatient Clinic of MIMS, Nellimarla, Vizianagaram during the period of May 2013 to May 2016. All patients are in the age group range from 20 to 60 years.

The Following Inclusion Criteria were used:

1. Chief complaint was low back pain with or without radiculopathy. 
2. The duration of low back pain was at least eight weeks and conservative treatment was unsuccessful. However, this criteria was waived off in few cases who showed sudden deterioration.

3. Patient was at least 18 yrs. old (no maximum age).

4. There was no history of acute trauma.

5. The patient had not undergone a lumbar spine surgery before.

6. No contraindications for MR imaging (e.g. pacemaker, metallic aneurysmal clips, etc.).

7. There was no metallic hardware in the lumbar spine (e.g. Harrington Rods).

Six patients otherwise eligible were excluded because of claustrophobia (4) or their inability to lie still in the MR scanner because of pain (2), hence they were not included in the list of study cases.

- MRI was performed on a Toshiba 0.2T MRI Scanner using spine - array coils.

- In all cases, the examination was performed in supine position.

- Each examination included an overlapping multi-slice technique.

- Sagittal T1W, T2W and STIR images were then acquired with Spin Echo (SE)/Turbo Spin Echo (TSE) and inversion recovery sequences. Thereafter, axial and/or coronal T1 and $\mathrm{T} 2$ weighted images were acquired through the levels revealing abnormality. However, axial T1 and T2 weighted scans were obtained through all lumbar disc levels in all the cases. Gadolinium enhanced MRI was done for four cases of spinal tumours and $\mathrm{T} 1+\mathrm{C}$ Sagittal and axial images were acquired.

- Other relevant investigations such as radiography chest, Mantoux test, blood count, ESR and USG abdomen were carried out where warranted to detect supportive evidence for the suspected disease condition.

- CT guided FNAC was performed where the requirement arose for a definitive histopathological diagnosis.

\section{OBSERVATIONS}

A total of two hundred and forty patients, either admitted or attending the outpatient clinic at Maharaja Institute of medical sciences and King George Hospital presenting with persistence of low back pain between December 2012 and September 2014 form the subjects of the study. Observations were made on the physical findings, plain radiograph report and MRI scan in each patient.

Of the 240 patients studied, 166 were males and 74 were females. The youngest patient was aged 21 years and the oldest patient was 60 years old.

Age and Sex Distribution of Studied Cases are Depicted in Table. 1 and Figure 1

\begin{tabular}{|c|c|}
\hline Age Group & Patients \\
\hline $20-29$ & 18 \\
\hline $30-39$ & 52 \\
\hline $40-49$ & 96 \\
\hline $50-59$ & 74 \\
\hline Table 1: Age and Sex Distribution of Studied Cases \\
\hline
\end{tabular}

There were maximum patients (41) in the 40 to 49 years age group (26\%) and minimum in 80 to 89 years' age group (2\%). Majority of the patients fell in age group (83\%). There were significantly less patients in more than 70 years' age group. In all the groups, there was a male preponderance.

Maximum number of patients are in the age group of 4049 , of these patients 52 patient's MRI study is within normal limits; 142 patients have degenerative disc disease and 24 patients had infective pathology (infective discitis), 2 patients had secondary deposits in the vertebral bodies; 20 patients have other findings like bony canal stenosis, hemivertebrae, block vertebrae or diastematomyelia or perineural cysts.

Distribution of Presenting Complaints in Study Population

\begin{tabular}{|c|c|c|}
\hline $\begin{array}{c}\text { Sl. } \\
\text { No. }\end{array}$ & $\begin{array}{c}\text { Presenting Complaint/ } \\
\text { Symptoms }\end{array}$ & $\begin{array}{c}\text { Total Number of } \\
\text { Patients }\end{array}$ \\
\hline 1 & Only low back pain & 146 \\
\hline 2 & LBP with sciatica & 55 \\
\hline 3 & $\begin{array}{c}\text { LBP with neurological } \\
\text { deficit + /- sciatica }\end{array}$ \\
\hline
\end{tabular}

As per the history and description of presenting complaints, the study population was classified into those with only low back pain, low back pain with sciatica and low back pain with sensory or motor deficit (+/-Sciatica).

\section{Type of MRI Abnormality in Studied}

\begin{tabular}{|c|c|c|}
\hline $\begin{array}{c}\text { Sl. } \\
\text { No. }\end{array}$ & Diagnosis & $\begin{array}{c}\text { Number } \\
\text { of } \\
\text { Patients }\end{array}$ \\
\hline 1 & Normal scan & 10 \\
\hline 2 & Degenerative & 142 \\
\hline 3 & Infective & 64 \\
\hline 4 & Congenital & 12 \\
\hline 5 & Neoplastic & 2 \\
\hline 6 & Miscellaneous & 8 \\
\hline & $\begin{array}{c}\text { Post-traumatic and post-operative: } \\
\text { None patients with history of trauma } \\
\text { and previous spinal surgery were not } \\
\text { included in the study }\end{array}$ & \\
\hline
\end{tabular}

In 20 to 29 years' age group most of them had infective diseases (16), degenerative changes (4), 2 had diastematomyelia and 2 patients had intradural extramedullary tumours.

\section{Degenerative Changes on MRI Prevalence in 142 Cases of} Low Back Pain

\begin{tabular}{|c|c|c|}
\hline $\begin{array}{c}\text { Sl. } \\
\text { No. }\end{array}$ & $\begin{array}{c}\text { Type of Degenerative } \\
\text { Changes }\end{array}$ & $\begin{array}{c}\text { Number of } \\
\text { Positive }\end{array}$ \\
\hline 1 & Disc degeneration & 102 \\
\hline 2 & Disc height reduction & 20 \\
\hline 3 & Disc herniation & 20 \\
\hline
\end{tabular}

The prevalence of various degenerative changes in the above mentioned table shows degeneration was found in 102 cases. Reduced disc height was seen in 20 cases. 

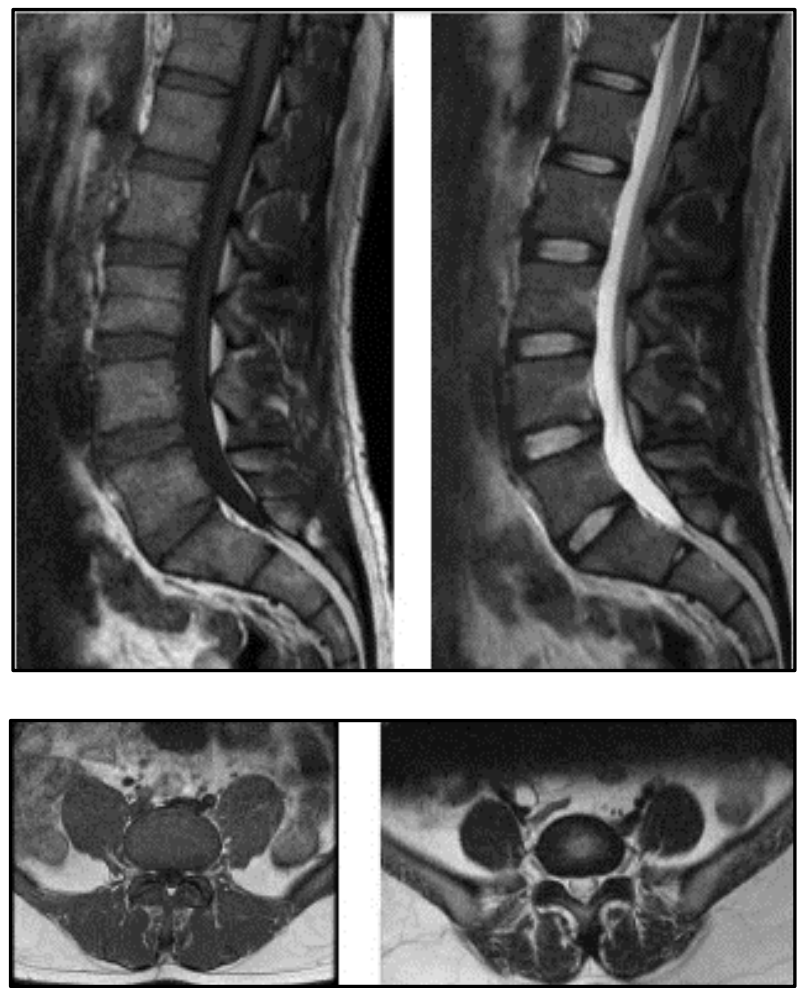

Normal Lumbar Spine on T1W and T2W Sequences
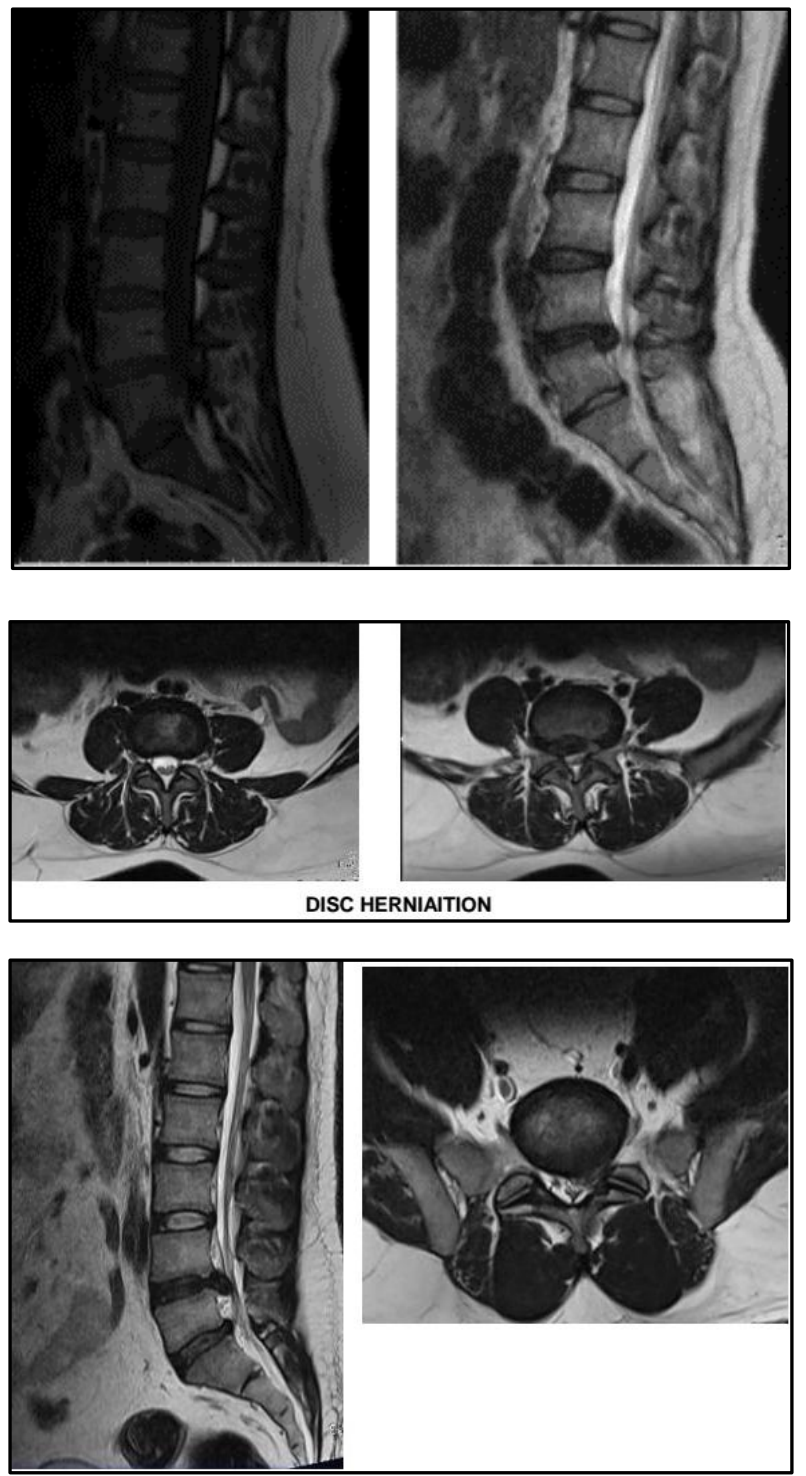
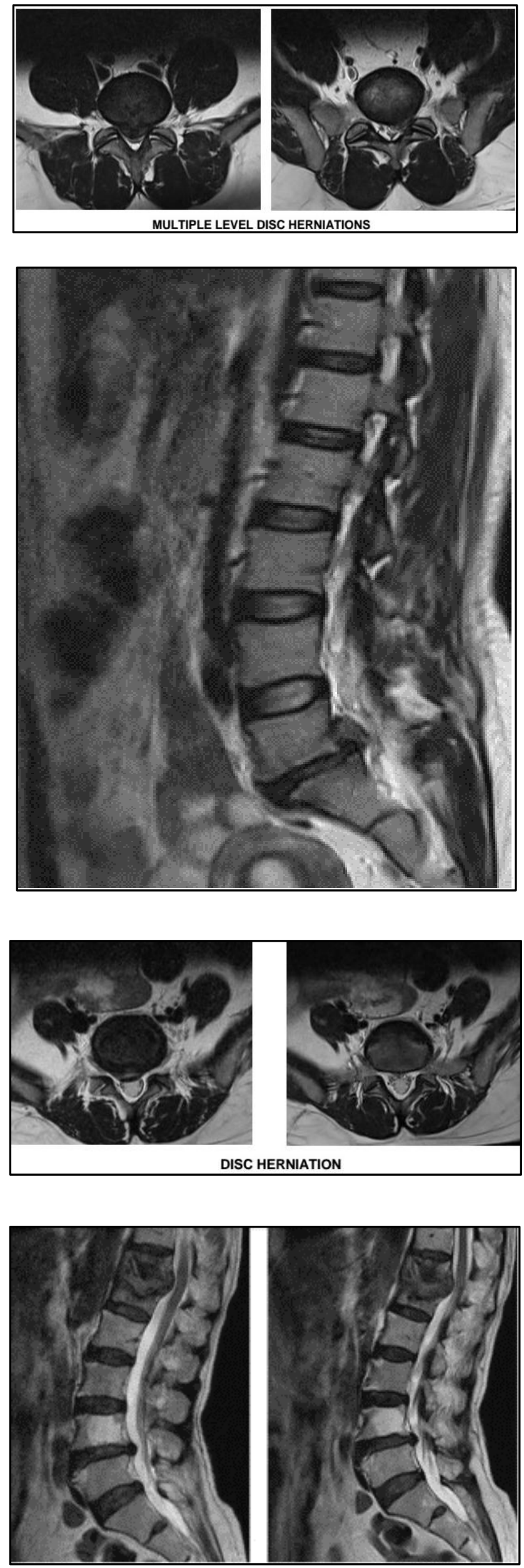

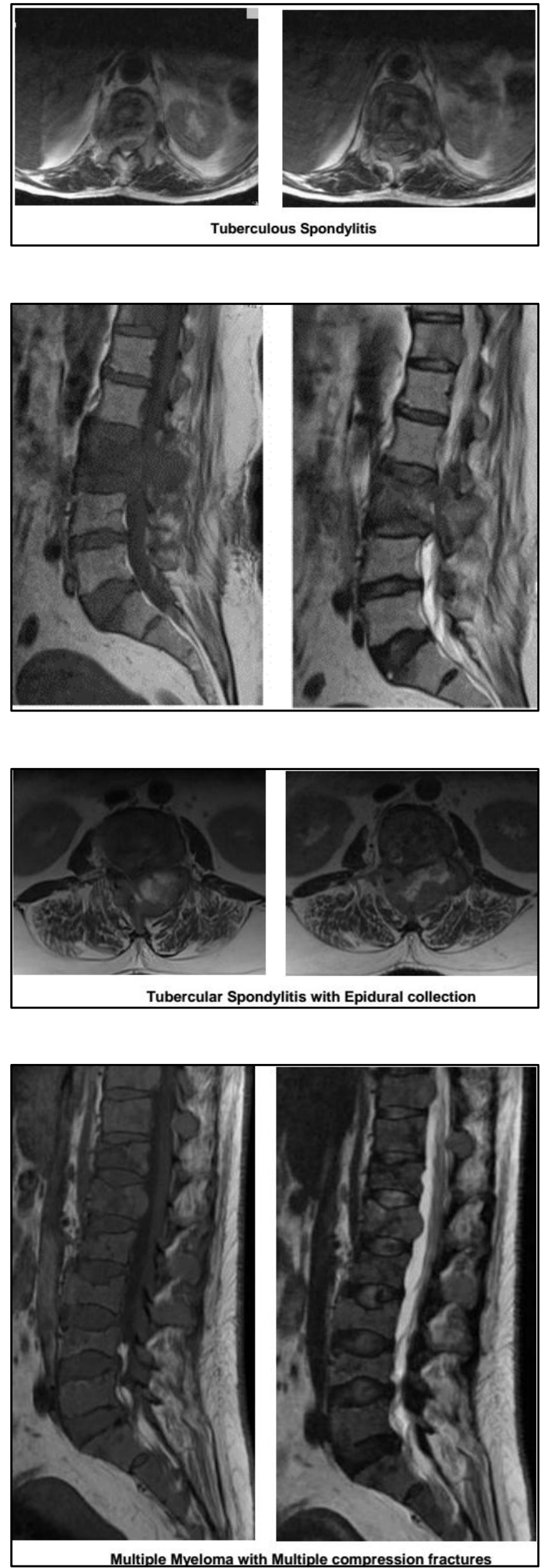

Multiple Myeloma with Multiple compression fractures
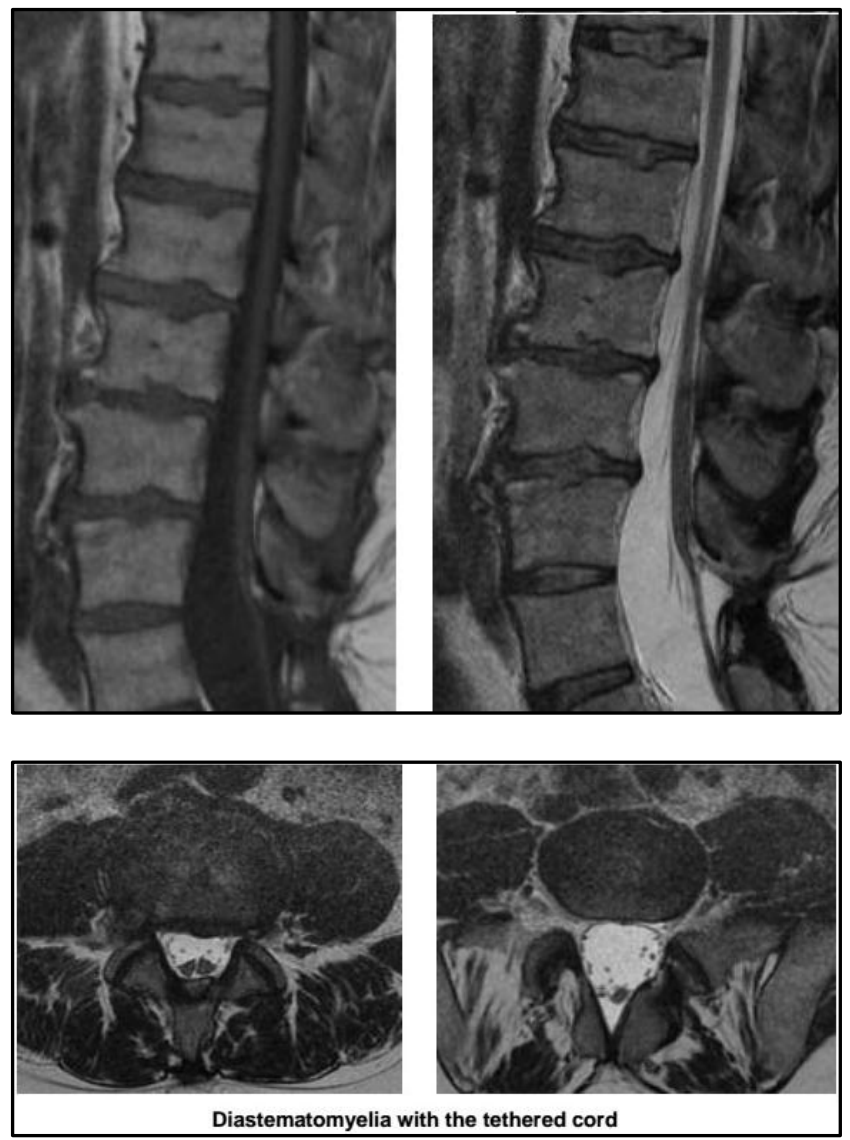

\section{CASE DISCUSSION}

Several reports have evaluated the role of Magnetic Resonance Imaging (MRI) in patients with low back pain ${ }^{[1]}$ and a number of MRI scans were abnormal in these studies. Low back pain is a common problem both in men and women and a major cause of chronic disability in the adult working population. It results in substantial loss in productivity and enormous health care expenditure.

The lifetime incidence of low back pain ranges from $50 \%$ to $70 \% .{ }^{[2]}$

MRI reliably identifies and localises the spinal abnormality non-invasively on an outpatient basis without any risk or morbidity.

In the present study, we evaluated 240 cases of presumed non-specific persistent low back pain between the ages of 20 to 60 years after screening with a thorough physical examination and plain radiograph of lumbosacral spine.

The plain radiographs, which were obtained were normal in ninety cases.

\section{Plain Radiographs}

Plain radiographs were normal in 135 of the 240 cases studied. The most common positive findings were reduced lumbar lordosis, which is seen in 94 cases. Other common positive radiographic features were narrowed disc space in 32 cases and osteophytosis and 40 cases. End plate changes were seen in 16 cases. Bone erosion was seen in three cases. Spondylolisthesis was seen in thirteen cases.

On MRI examination, disc degeneration was found in 69 of the 142 cases for which radiographs were normal. Thus, it is evident that plain radiographs have low sensitivity in detecting or predicting early disc degeneration. Similar findings were reported by Pajanen et al.[3] Retrospectively, we 
observed that the plain radiographs were normal in 6 out of the 8 cases of osteomyelitis and 5 out of the 7 cases of osteomyelitis and 4 of the 5 cases with spinal neoplasms as well.

Altered lumbar spine curvature (reduced lumbar lordosis or hyperlordosis) was a nonspecific finding with no significant association with disc degeneration or infective/neoplastic pathologies. Reduced lumbar lordosis was found more often than hyperlordosis.

Narrowed disc space was always associated with disc degeneration in our study. Similarly, end plate sclerosis was nearly all the time associated with disc degeneration.

\section{Degenerative Changes}

A majority of the studied cases fell under the degenerative disorders group. A total of 86 cases out of the 142 cases with low back pain studied revealed degenerative changes on MRI. Degeneration of at least one lumbar disc was found in each of these cases. Hannupanjanen et al reported 57\% incidence of disc degeneration in low back pain cases.

The degenerative changes suspected on radiographs in 37 cases were confirmed in all the cases, but in addition 49 more cases were detected to have disc degeneration and other degenerative changes. This observation suggests that early degenerative changes do not manifest on plain radiographs and also that MRI is highly sensitive in detection of early disc degeneration.

Savage et al[4] conducted a study in 1997 and reported disc degeneration in a little more than half (53\%) of the LBP cases, which is very similar to the figures in our study. They also reported that L5-S1 was the most commonly degenerated disc, where $31 \%$ of the discs at that level were found degenerated which coincides with our study in which there were 77 patients with disc degenerations at L5-S1 level and 50 patients with disc degenerations at L4-L5 level.

In the patients less than 50 years, most disc generations are present in L4-L5 and L5-S1 and none at L1-L2 and L2-L3. In the age group of 50 years and above, L1-L2 and L2-L3 were found degenerated along with the caudal 3 levels which coincides with the study of Panjanen et al.[3]

\section{Disc Degeneration of MRI}

At least one lumbar disc, each was found degenerated in 102 cases and disc height was found reduced in 31 cases. The most common level of disc degeneration was L5-S1 followed by L4L5. Our findings are in consonance with the study conducted by Pajanen et al[3,5] in 1989. They reported that the most common levels of disc degeneration were L5-S1 followed by L4-L5.

They did not specify about the correlation of end plate degeneration changes and disc degeneration on MRI in their study.

In our cases a correlative study of the physical signs and disc degeneration on MRI revealed that out of the 34 cases with a positive 'straight leg raising' test 29 showed disc degeneration and of the 71 cases with restricted lumbar mobility 63 showed disc degeneration. Similar strong correlation was also found between motor weakness and disc degeneration.

It is seen that with increasing age, the prevalence of disc degeneration increases. In 20-29 years' group, $22.2 \%$ cases (4 out of 18) had disc generation.
In 40-49 years' group, $50 \%$ cases (48 out of 96 ) had disc degeneration. In 50 to 60 years' group, $67 \%$ cases (50 out of 74) had disc degeneration.

Similar findings have been reported by Savage et al and other studies reported 27\% prevalence in 20-30 years' age group and $52 \%$ in 31-50 years' age group.

Many authors believe that disc degeneration is a normal consequence of ageing and biochemical and structural changes occur simultaneously during ageing and degeneration. Cervionke believes that $35 \%$ patients between 20 and 39 years and virtually all patients over 60 years have disc degeneration on MRI.

Savage et al ${ }^{[4]}$ reported that the number of degenerated discs in the older group was greater at every disc level. There were 20 cases above sixty years age in our study and all of them had disc degenerations in MRI and 28 patients of thirty between 50-59 years had disc degenerations.

In our study, the most common level of disc degeneration was L5-S1 followed by L4-L5 together. These two levels accounted for $75 \%$ of the degenerated discs. The least common lumbar disc found degenerated was L1-L2 (7 cases, 4\%) similar statistics have been reported by other investigators, Panjanen $\mathrm{H}$ et al and Hansson T et al.,[3,6]

\section{Lumbar Disc Herniation}

In our study, 20 discs were found herniated.

Disc protrusion was the most common type of herniation found in 52\% followed by protrusion in 33\% and sequestration in $15 \%$ cases.

The most common level of disc herniation was L5-S1 (54\%) followed by L4-L5 (42\%). Disc herniation at L3-L4 was significantly less (10\%). We found no disc herniation at L1-L2 or L3-L4 levels.

Similar findings were reported by Jackson et al[7] and Crock.[8]

Jackson et al reported most frequent herniation of L4-L5 (50.8\%) followed by L5-S1 (42.4\%) and L3-L4 (6.8\%). They found that over one half $(52.5 \%)$ of the herniations operated were extrusions, $30.5 \%$ protrusions and $17 \%$ sequestrations. Crock ${ }^{[8]}$ opines that disc herniation occurs most commonly at lower lumbar levels, 90\% at L4-L5 and L5-S1, 7\% at L3-L4 and remaining $3 \%$ at the upper levels.

Savage et al[4] reported a $22 \%$ prevalence of disc herniation in all the study cases together (with and without low back pain). They found no herniation at L1-L2 and L3-L4 and maximum herniations were at L5-S1 level.

To overall PPV of MRI in correctly diagnosing the level and type of disc herniation was found to be $80 \%$. In our study, we found an MRI accuracy of $76.9 \%$ sensitivity of $84.8 \%$ and specificity of $63.2 \%$. Our findings are comparable to and in consonance with various other studies reported in literature. Jackson et al have reported a sensitivity of $76.5 \%$ in diagnosing herniated lumbar discs by MRI.

Hashinoto et al[9] have reported a sensitivity and specificity of $10 \%$ for MRI in diagnosing unilateral single disc herniation. Albeck et al compared the various radiological in their efficacy to detect disc herniation. They examined 80 patients of suspected lumbar disc herniation by MRI, myelography and $\mathrm{CT}$, all of whom underwent subsequent surgery.

Modic et al[10,11,12] have reported an MRI accuracy of 82-6\% in lumbar disc herniation in their study. In our study in correlation with the surgical findings in operated cases there 
was a sensitivity of $94.8 \%$, specificity of $63.2 \%$ and accuracy of $76.9 \%$ which correlates with the findings of Modic et al.

\section{Spinal Canal Stenosis}

In our study, we found 26 cases with spinal stenosis out of 142 (18.3\%).

Three cases were detected to have reduced sagittal lumbar canal diameter on plain radiographs and lumbar canal stenosis was suspected. On MRI, all 3 were confirmed to have stenosis with congenitally short pedicles present and another case with bony canal stenosis was detected.

\section{Infective Disorders}

In our study, 64 cases were diagnosed to be of infective aetiology. (All the cases had vertebral osteomyelitis).

Pyogenic spondylodiscitis represents approximately 2 to $4 \%$ of all cases of osteomyelitis.[13,14]

On MRI, a definitive diagnosis of infective spondylitis and strong likelihood of tubercular aetiology was given in 50 cases. In other 14 cases infective spondylitis was suspected, but the imaging features were not typical to give a definitive diagnosis. CT guided Fine Needle Aspiration Cytology (FNAC) was performed in 4 cases requiring confirmation.

The cases fell in relatively younger age group with all cases less than 40 years.

All the cases had presented with low back pain of insidious onset and more than two months of duration. None of the cases had fever or weight loss, though two cases reported decreased appetite. Local tenderness was elicited in three of the eight cases, straight leg raising was positive in four cases, paraspinal muscular spasm was found in five cases and lumbar mobility was restricted in seven cases. None of the case had neurological deficit, but sluggish ankle jerk was found in one case.

On routine investigations ESR was normal in two cases, marginally elevated in two cases and significantly elevated in one case. Chest radiographs taken in all cases were found normal.

\section{SUMMARY AND CONCLUSION}

Low back pain with or without sciatica is a very common ailment in the adult population resulting in chronic disability, loss in productivity and enormous health care expenditure. At some time in their life, almost $70 \%$ to $80 \%$ of all people will experience low back pain.

In majority of the cases, low back pain responds to conservative treatment in eight to ten weeks' period.

The most common causes of low back pain are degenerative disorders of the spine leading to disc herniation, facet joint arthropathy and lumbar canal stenosis.

Serious pathologies such as vertebral osteomyelitis, metastatic vertebral lesions, primary neoplasms of vertebrae and intradural tumour may present only with persistent low back pain without altering biochemical/haematological parameters or manifesting on plain radiographs. Pelvic or lower abdominal pathologies may manifest with low back alone.

Early imaging is required in cases of trauma and those with suspected infective or neoplastic lesions. In other cases imaging is restored if there is no response to conservative treatment, pain is severe and unrelenting or there is associated radiculopathy or myelopathy with the aim of detecting treatable causes. We found only 2 patients out of 240 have suffered from neoplastic diseases (multiple myelomas).

Magnetic resonance imaging serves as a non-invasive and highly sensitive method for evaluating the spine in the presence of low back pain.

On MRI, disc degeneration and other degenerative changes are the most common abnormalities found in cases of low back pain. Lumbar disc herniation is a common phenomenon found in such cases. How far these changes contribute to low back pain is still a matter of debate.

MRI has a high sensitivity in detecting and differentiating lesions of varied aetiology such as degenerative changes (Disc degeneration, Disc herniation, vertebral endplate changes and ligament hypertrophy and facet joint arthropathy), infective lesions and tumours, congenital and developmental disorders, compression fractures and many other uncommon pathologies of the spine. In our study, we found MRI sensitivity of $100 \%$ in cases of infective spondylitis and neoplastic lesions of the spine.

MRI has a high accuracy in diagnosing lumbar disc herniation and is capable of distinguishing sequestered disc herniations from contained or subligamentous disc herniations. With the development of minimally invasive treatments for herniated discs, such as intradiscal enzyme therapy, percutaneous nucleotomy, arthroscopic discectomy and endoscopically assisted transformational excision of the disc, the need to distinguish sequestered from subligamentous disc herniations is critical.

Hence, in future MRI may assume a decisive role in the management of herniated discs. In vertebral osteomyelitis MRI shows quite characteristic appearance, facilitating a reliable diagnosis. It provides significant anatomic information regarding the thecal sac and neural structures. It is excellent modality to detect and localise epidural collections and level of cord compressions.

Changes of vertebral osteomyelitis appear earlier on MR images than on plain radiographs. It is useful in distinguishing metastatic disease, primary neoplasms of vertebral bodies, degenerative changes and compression fractures from active osteomyelitis by lack of confluent involvement of vertebral bodies and intervening discs. Only $27 \%$ approximately of the cases (64 out of 240) suffered from caries spine in our study.

We found out that infective aetiology with majority of the patients suffering from tuberculosis of spine is more prevalent in rural population. This we assume that it is due to their low socioeconomic and poor nutritional conditions.

A sagittal T1/T2 weighted sequence can rapidly screen the whole of dorsolumbar spine for multiple skip lesions and localise the level of abnormality.

Some of the advantages of MRI over conventional imaging in imaging of the spine include: 1 ) The ability to recognise disc degeneration even in its earliest stages. Direct visualisation of the spinal cord without the need for intrathecal contrast injections, 2) Multiplanar imaging capability and imaging in the sagittal plane without the need for reformatting (as is required CT), 3) No exposure to ionising radiation, 4) Lack of $\mathrm{X}$-ray beam hardening artifact, which often limits the effectiveness of CT in imaging of the spine.

\section{The Limitations of Magnetic Resonance in Imaging are:} In General

1. The high cost of the examination. 
2. The relatively time consuming nature of investigation.

3. Inability to scan patients who cannot lie still, e.g. infants, young children.

4. Comatose patients and those with severe pain.

\section{In Examination of the Spine:}

1. Limited assessment of cortical bone and bony spurs.

2. Inability to differentiate osteophytes from small degenerated disc herniation.

3. Inability to distinguish between cortical bone, bony spurs and ligamentous structures and between peripheral annulus fibrosus and the posterior longitudinal ligament.

In our study, we find no much difference in the pattern of aetiology for low backache in rural folk.

In our study, we found that in rural population also we found that degenerative disc disease in the major cause for low backache.

In spite of their poor socio-economic condition and poor diet and unhealthy environments surrounding their poor villages we found no much increase in the incidence of tuberculosis/infective aetiology involving spine.

In our study, we also found that 52 patients (21\%) are having normal MRI scans (reason for low backache is mechanical rather than pathological aetiology).

So we conclude that even though MRI is over-suggested to evaluate low backache, it is the study of choice for evaluating low backaches because of its high sensitivity and specificity.

\section{REFERENCES}

1. Maravilla KR, Cohen WA, Wessbecher FW. Imaging studies in the assessment of low back pain. Neurosurg Clin North Am 1991;2(4):817-37.

2. Kendall BE. Neuroradiology of the spine. $5^{\text {th }}$ ed. In: Textbook of radiology and medical imaging. David S (ed). Churchill Livingstone. Edinburgh 1992:1407-44.
3. Paajanen $H$, Erkintalo $M$, Kuusela $T$, et al. Magnetic resonance study of disc degeneration in young low back pain patients. Spine 1989;14(9):982-5.

4. Savage RA, Whitehouse GH, Roberts N. The relationship between the magnetic resonance imaging appearance of the lumbar spine and low back pain, age and occupation in males. Eur spine J 1997;6(2):106-14.

5. Albeck MJ, Vilden J, Kjaer L, et al. A controlled comparison of myelography, CT and MRI in clinically suspected lumbar disc herniaton. Spine 1995;20:443-8.

6. Hansson T, Bigos S, Beccher P, et al. The lumbar lardosis in acute and chronic low back pain. Spine 1985;10(2):154-5.

7. Jackson RP, Cain JE, Jacob RR, et al. The neuroradiographic diagnosis of lumbar herniated pulposes II. A comparision of CT, CT myelography, myelography and MRI. Spine 1989;14(12):1362-7.

8. Crock HV. Internal disc disruption. A challenge to disc prolapse fifty years on. Spine 1986;11(6):650-3.

9. Hashimopto K, Akahori O, Kitano K, et al. Magnetic resonance imaging of lumbar disc herniation. Comparision with myelography. Spine 1990;15(11):1166-9.

10. Modic MT, Steinberg PM, Ross JS, et at. Degenerative disc disease: assessment of changes in vertebral body marrow with MR imaging. Radiology 1988;166(1 Pt 1):193-9.

11. Modic MT, Masaryk T, Boumphery F, et al. Lumbar herniated disc disease and canal stenosis: prospective evaluation by surface coil MR, CT, and myelography. AJR 1986;147(4):757-65.

12. Modic MT, Masaryk T, Paushter D. Magnetic resonance imaging of the spine. RCNA 1986;24(2):229-45.

13. Dagirmanjian A, Schills J, McHenry MC. MR imaging of spinal infections. Magn Reson imaging Clin $\mathrm{N}$ Am 1999;7(3):525-38.

14. Lederman HP, Schweizer ME, Morrison WB, et al. MR imaging findings in spinal infections: rules or myths. Radiology 2003;228(2):506-14. 